REVESCO. Revista de Estudios Cooperativos

ISSN: $1885-8031$

https://dx.doi.org/10.5209/REVE.71859

\title{
Persona Cooperativa en un contexto de transformación educativa y social ${ }^{1}$
}

\author{
Oxel Azkarate-Iturbe ${ }^{2}$; Jose Ramón Vitoria Gallastegui ${ }^{3}$; ; Aitor Aritzeta $\operatorname{Galan}^{4} \mathbb{C}^{-}$e Iban \\ Galletebeitia Gabiola ${ }^{5}$
}

Recibido: 4 de marzo de 2020 / Aceptado: 11 de junio de 2020 / Publicado: 23 de noviembre de 2020

Resumen. El objetivo del presente artículo es definir y caracterizar el perfil de la denominada "Persona Cooperativa" (PC) dentro de las instituciones educativas, facultades universitarias y empresas vinculadas al ámbito educativo cooperativo y dentro del ecosistema cooperativista del País Vasco. Para alcanzar dicho objetivo se realizó una investigación cualitativa mediante el método de la Teoría Fundamentada. Después de constatar que el concepto PC a analizar no es nuevo, la revisión bibliográfica realizada en las principales bases de datos (WOS, Scopus...) no ha aportado una clara definición ni caracterización del perfil. De este modo, se llevaron a cabo 4 entrevistas semiestructuradas, observaciones panorámicas no participantes (14 sesiones, 30 profesionales) y análisis de documentos internos en 3 de las organizaciones participantes en el estudio. El análisis y la triangulación de datos se ha efectuado mediante el método comparativo constante hasta lograr la saturación teórica. El trabajo de investigación ha permitido, por un lado, situar los valores y actitudes individuales, cooperativos y comunitarios como Categoría Central y, por otro, clasificarlo en tres categorías conceptuales principales: ser autosuficiente, ejercer la cooperación y ser emprendedora socio-comunitaria. Entendemos que este trabajo puede contribuir a establecer las bases para el desarrollo del perfil de PC y su evaluación con la implementación de programas educativos asociados a las dimensiones personales, relacionales y socio-comunitarios que lo definen.

Palabras clave: Innovación educativa; Análisis cualitativo; Competencias para la Vida; Educación cooperativa; Valores.

Claves Econlit: I20; P13; A13; M14.

\section{[en] Cooperative person in a context of educational and social transformation}

\begin{abstract}
The objective of this article is to define and characterize the profile called "Cooperative Person" (CP) in educational institutions, university faculties and enterprises within the cooperative educational ambit of the cooperativist ecosystem in the Basque Country. To achieve this objective, qualitative research was conducted using Grounded Theory. Although this is not a new concept, the literature review of main databases (WOS, Scopus...) has not provided a clear definition or characterization of the profile. Thus, 4 semi-structured interviews, non participant panoramic observations (14 sessions, 30 professionals) and internal document analysis were carried out in 3 of the organizations participating in the study. Triangulation and analysis of data were performed using the constant comparative method, until theoretical saturation was achieved. The research work has allowed, on the one hand, to place individual, cooperative and community values and attitudes as a central category and, on the other, to classify it into three main conceptual categories: to be self sufficient, to exercise cooperation and to be socio-community entrepreneur. We believe that this work can contribute to establishing the basis for the development of the CP profile and its evaluation, with the implementation of educational programs associated with the personal, relational and socio community dimensions that define it the profile.
\end{abstract}

Keywords: Educational innovations; Qualitative analysis; Life skills; Cooperative education; Values.

Sumario. 1. Introducción. 2. Perfil de personas para el siglo XXI en un contexto de trasformación educativa y social. 3. Revisión de Persona y Cooperación. 4. Proyectos para la trasformación educativa y social en el contexto vasco. 5. Objetivos. 6. Método. 7. Resultados. 8. Discusión y conclusión. 9. Referencias bibliográficas.

1 Este proyecto de investigación fue financiado por la Excma. Diputación Foral de Guipúzcoa a través de su Programa para la Promoción de personas y empresas participativas en Gipuzkoa. ZK: Partaidetza-IGB-24. Nos gustaría agradecer a la Fundación Gizabidea y a la Fundación ULMA por su respaldo y apoyo al proyecto, y a todas aquellas personas y organizaciones que participaron de una manera u otra en el proyecto de investigación.

2 Mondragon Unibertsitatea, España.

Dirección de correo electrónico: oazkarate@mondragon.edu.

Mondragon Unibertsitatea, España.

Dirección de correo electrónico: irvitoria@ mondragon.edu.

4 Mondragon Unibertsitatea, España.

Dirección de correo electrónico: aitor.aritzeta@ehu.eus.

5 Universidad del País Vasco, España.

Dirección de correo electrónico: igalletebeitia@gmail.com. 
Cómo citar. Azkarate-Iturbe, O.; Vitoria Gallastegui, J.R.; Aritzeta Galan, A.; Galletebeitia Gabiola, I. (2020) Persona Cooperativa en un contexto de transformación educativa y social. REVESCO. Revista de Estudios Cooperativos, vol. 136, e71859. https://dx.doi.org/10.5209/reve.71859.

\section{Introducción}

El siglo XXI ha traído consigo la necesidad de adquirir nuevos perfiles personales y profesionales expresados mediante la adquisición y desarrollo de habilidades y competencias entendidas como necesarias para la vida (Care, Griffin \& Wilson, 2018; Armijo, 2018; Anagün, 2018). En este sentido, muchos centros educativos han iniciado programas para transformar sus modelos educativos mediante nuevos marcos pedagógicos centrados en el desarrollo integral de la persona. Estas transformaciones requieren de diferentes tipos de innovaciones y/o cambios tanto personales, organizacionales como estructurales de los centros de enseñanza y formación profesional. En tales programas, la misión educativa se ha re-definido y se ha relacionado con un perfil específico adaptado a las demandas del siglo XXI, en este estudio en concreto, el perfil de Persona Cooperativa. De este modo, se hace necesario indagar (también, dentro del ecosistema cooperativista del País Vasco) en la definición y caracterización del perfil de Persona Cooperativa con el fin de identificar las claves para su desarrollo y evaluación. De esta manera, se podrá seguir co-creando el progreso de estas transformaciones mediante proyectos diseñados, implementados e investigados con los centros y las facultades, y así continuar desarrollando propósitos comunitarios trasformadores desde la comunidad educativa y perspectiva eco-sistémica.

Esta necesidad "local" identificada concuerda y coincide con la necesidad de investigar las diferentes orientaciones planteadas desde distintos ámbitos educativos, sociales y económicos internacionales (National Research Council, 2012; World Economic Forum, 2016; OCDE, 2015; OCDE, 2019). Este estudio se centra por lo tanto en los perfiles personales y profesionales como en los comportamientos humanos cooperativos. A continuación, se exponen las conexiones entre dichas ideas.

\section{Perfil de personas para el siglo XXI en un contexto de trasformación educativa y social}

Las condiciones que caracterizan la sociedad actual de la información y el conocimiento como la globalización, la digitalización, el colapso ecológico y el cambio climático orientan el progreso del mundo hacia una transformación sin precedentes y lleno de incertidumbres (UTRU world) (Harari, 2018). Por ello, se hacen necesarias nuevas propuestas, como la planteada por Kate Raworth (2018), que ayuden a transformar los modelos socioeconómicos basados en el bienestar humano y la naturaleza. Ayudaría en ello, el desarrollo de actividades que sean generativas y distributivas desde su origen. Por lo tanto, la ciencia socioeconómica necesita construir otra narrativa global basada en otros modelos de personas, con otros valores y actitudes personales y sociales.

El carácter multidimensional de la crisis, más allá del modelo económico, afecta a las formas de participación en la vida pública, las formas de relación entre las instituciones y la ciudadanía, además de los valores éticos y morales que subyacen a nuestros comportamientos sociales. Estos cambios requieren de la innovación social, entendiendo ésta como factor de transformación social. Por esa razón, se exige, entre otras dimensiones, el empoderamiento ciudadano (Martínez, Cruz, Blanco y Salazar, 2019) y una educación para la ciudadanía global como eje para la transformación social (Blasco Serrano, Dieste y Coma, 2019).

Todas estas características del contexto están influyendo, por un lado, en que la educación, con perspectiva de aprendizaje para toda la vida y para todas las personas de la comunidad, también ayude en la respuesta a los retos económicos, sociales y medioambientales a los que se enfrenta la sociedad con el fomento y desarrollo de competencias y habilidades necesarias para las personas del siglo XXI. En este caso, y desde diferentes ámbitos, se mencionan como importantes algunas competencias y habilidades que requieren del pensamiento crítico (capacidad de plantear muy buenas preguntas), la cooperación (el trabajo en común), la comunicación (oral, escrita y saber escuchar) y la autogestión. Todas ellas reconocidas esenciales para resolver situaciones problemáticas de forma creativa e innovadora. Estas competencias deberán asumir características concretas como empatía, persistencia, firmeza, autodisciplina y una visión poderosa de la vida moral, entre otras (Wagner, 2012; National Research Council, 2012).

Por su parte, la Organización para la Cooperación y el Desarrollo Económico (OCDE, 2015), para definir el perfil de personas para el siglo XXI, destaca la importancia de desarrollar una persona integral, con habilidades cognitivas, sociales y emocionales que permitan favorecer el bienestar y el avance social. A su vez, el Foro Económico Mundial (World Economic Forum, 2016) plantea emprender una nueva visión de la educación, destacando la importancia que contienen la capacidad de cooperación, comunicación y resolución de problemas relacionados con las competencias sociales y emocionales; sin dejar de lado el desarrollo de otras competencias tradicionales. De acuerdo con esto, Ginevra Musicco (2018) añade que, las universidades 
europeas tratan de desarrollar las competencias blandas a través de la empleabilidad y el coaching, y mientras, el mercado parece buscar personas flexibles, capacitadas, creativas, innovadoras, responsables, versátiles e integradoras.

Posteriormente, la actualización de la Estrategia de Competencias de la OCDE (2019) sitúa las competencias como elemento fundamental para el progreso humano. Hace énfasis en la importancia de desarrollar las competencias sólidas a lo largo de la vida con una perspectiva inclusiva tanto en los centros educativos, educación superior, en la comunidad y en el trabajo para de esa manera garantizar el bienestar y promover el crecimiento incluyente y sostenible de sociedades y economías que están cada vez más digitalizadas. Igualmente, subraya el valor de desarrollar competencias efectivas que implican la movilización de valores, actitudes, conocimientos y habilidades, las cuales serán importantes para conseguir éxito en el trabajo y en la sociedad satisfaciendo demandas cada vez más complejas e inciertas. El desarrollo de estas competencias efectivas permitiría que las personas sean trabajadoras competentes y ciudadanas comprometidas y activas. Asimismo, se resalta la importancia de elaborar procedimientos de evaluación sistemáticos de los programas de aprendizaje. Para ello, propone el uso de herramientas como el análisis de impacto con diseños experimentales para evaluar el progreso de los perfiles profesionales de las personas.

Del mismo modo, cabe mencionar, la existencia de un consenso a nivel internacional en cuanto a las competencias y habilidades para el siglo XXI que necesitan desarrollar los estudiantes para enfrentar los desafíos del mundo contemporáneo. De entre estas competencias y habilidades, la resolución de problemas, el pensamiento crítico, la cooperación, la comunicación y la creatividad se definen como las principales. De esta manera, la cooperación se sitúa como una forma de enfatizar lo colectivo, relacionándose con la convivencia, el clima del aula, la inclusión y la educación ciudadana (Armijo, 2018; Anagün, 2018).

Estas competencias y habilidades necesarias para la vida de las personas han ido integrándose en los diferentes currículos universitarios y escolares desde, por ejemplo, la Declaración Conjunta del Espacio Europeo de Educación Superior (Declaration Bologna, 1999) o el Consejo Europeo de Lisboa de 23 y 24 de Marzo de 2000, recogió como el marco de referencia europeo las cualificaciones básicas que debe proporcionar el aprendizaje permanente como medida esencial ante la globalización y el desplazamiento hacia las economías basadas en el conocimiento, subrayando que la principal baza de Europa son las personas (Consejo de la Unión Europea, 2006).

En este contexto, a pesar de la importancia que tiene la cooperación, de los rasgos distintivos de la sociedad de este siglo, se alerta de la aparición de una nueva persona, un ser humano solitario que no sabe gestionar el compromiso social y que ha perdido el deseo de cooperar. Una persona con un tipo de carácter emergente en la sociedad moderna, un yo no cooperativo (Sennett, 2012). Esto, puede influir negativamente en la persona y en la comunidad, porque la ciudadanía también conlleva una forma de vida que reclama compartir valores y normas para poder cumplir las responsabilidades comunes de la sociedad (Puig y Morales, 2015). Por ello, se hacen necesarias investigaciones que profundicen en modelos de comportamiento humano cooperativo que den respuesta a los retos de la sociedad actual.

\section{Revisión de Persona y Cooperación}

La cooperación siempre ha sido un factor positivo y natural en la evolución humana. La ayuda mutua basada en la solidaridad y cooperación afecta el progreso y el bienestar de la comunidad y de la persona. Los seres humanos han avanzado cooperando y la interacción de la comunidad ha sido importante en esta supervivencia. La conciencia moral es complemento referencial del humano y la ayuda mutua ha sido quien ha desarrollado la evolución ética, no la lucha por la existencia (Kropotkin, 1902, 1993).

Por ello, y con objeto de identificar las claves entre la cooperación y las personas, resulta necesaria la definición de cada uno de sus términos y, a su vez, de un análisis de ellos desde diferentes perspectivas: filosóficas, biológicas, sociobiológicas, socioeconómicas...

A nivel filosófico, Azurmendi (2016) encuentra diferentes perspectivas para abordar el tema de la naturaleza humana, persona y cooperación, preguntándose si el ser humano es cooperativo altruista o egoísta, y apuntando a la posibilidad de una posible escala gradual entre el extremo del egoísmo y el altruismo.

Por otro lado, desde un punto de vista biológico, la cooperación ha sido un concepto clave para entender la vida misma. Los principios básicos de la evolución son la mutación y la selección natural, pero la evolución se construye con la cooperación. Mediante la cooperación, la cual fomenta el progreso de unos y otros, el individuo logra mejores resultados que los que obtendría solo. Así, se distinguen cinco factores de cooperación que tan solo los seres humanos tienen la capacidad de usarlos en la globalidad: reciprocidad directa, reciprocidad indirecta, juegos espaciales, selección de grupos y selección de parentesco (Nowak, 2006; Nowak \& Highfield, 2011). Cada animal social tiene que conseguir el equilibrio entre la persona y la comunidad. Los seres humanos, al ser producto de fuerzas opuestas, tienen la necesidad tanto de cuidar los intereses personales como de actuar juntos: dos factores que están estrechamente relacionados que ayudan a sobrevivir (De Waal, 2007). 
Por su parte, la sociobiología profundiza en el análisis del comportamiento moral y social de las personas desde un punto de vista biológico. En esta perspectiva, una corriente defiende que la esencia de la vida y la razón para la cooperación se basa en el egoísmo de los genes reproductores (Dawkins, 1976). Por el contrario, otros afirman que los humanos son cooperativos, eusociales o pro-sociales. Hacen hincapié en que quienes superan la lucha por la existencia son los grupos, no los individuos. Por consiguiente, la selección de grupos es la base de la evolución, esto es, la evolución es de todo el grupo no es solo individual o familiar. Es por ello, que la evolución de la cultura causa la biología genética y la evolución de la biología genética en la cultura (Wilson \& Wilson, 2007; Wilson, 2012). A este respecto, Tomasello (2007) añade que esta transmisión social y cultural ocasiona cambios biológicos provocando una evolución cultural acumulativa en seres humanos, basado en el "efecto trinque". Así, se construye una forma especial de cognición social, una doble herencia biológica y cultural. Por ello, los humanos, en contra de los animales, tenemos capacidad de ponernos en el lugar mental del otro. En consecuencia, el ser humano es un ser social que tiene capacidad de actuar y de pensar cooperativamente en grupos culturales. De ahí la importancia de las relaciones sociales. Desarrollamos un tipo especial de inteligencia cultural, con habilidades para cooperar, comunicar y aprender socialmente tomando formas de intencionalidad compartida. Habilidades que construyen la capacidad de participar en un pensar grupal cooperativo. Además de las habilidades cognitivas sociales son importantes la coordinación y la comunicación, la tolerancia y la confianza, y las normas sociales y las instituciones (Tomasello, 2010). Del mismo modo, la cognición y la sociabilidad humana serán cada vez más cooperativas y más autosuficientes a medida que los individuos se vuelvan más interdependientes. El éxito de la cooperación está afectado por las habilidades comunicativas de la persona, las relaciones, el desarrollo de capacidades y motivación, y los aspectos emocionales: sobre todo, para crear y desarrollar mentalidad grupal y mentalidades intencionales colectivas. Porque la cooperación es necesaria para el bienestar de todos (Tomasello, Melis, Tennie, Wyman \& Herrmann, 2012; Melis y Tomasello, 2019). Por lo tanto, vivir en un sistema social más igualitario y un temperamento más humano puede ser un precedente para la evolución de las habilidades cooperativas humanas (Melis, Hare \& Tomasello, 2006).

De otra parte, la neurociencia, permite analizar las bases neuronales más allá de los límites del comportamiento social humano. Desde esta disciplina, los seres humanos somos una especie social; dado que nuestra naturalidad social humana nos hace ser humanos conscientes, y esto tiene su reflejo en el cerebro. Y es que están relacionadas entre sí la emoción y la razón, la acción y la percepción y la representación entre otras personas y nosotros mismos. Las regiones cerebrales se basan en los razonamientos del comportamiento social humano, las orientaciones voluntarias, las respuestas a la autorregulación y las acciones emocionales, integrándolas y relacionándolas con el comportamiento que persiguen los objetivos del pensamiento humano (Adolphs, 2001; 2003). Así, los comportamientos sociales humanos son esenciales para mantener relaciones y exigen comprender y pensar en algunas inteligencias de otras personas (Kliemann \& Adolphs, 2018). Para ello es importante la empatía, ya que influye en la experiencia emocional grupal (Weisz \& Zaki, 2018; Vollberg \& Cikara, 2018). De hecho, la empatía se basa en las neuronas espejo que se van construyendo progresivamente a lo largo de la evolución (Swaab, 2014). En definitiva, estos procesos del cerebro, relacionados con el comportamiento social humano, pueden contribuir a identificar las claves del aprendizaje y a promover el bienestar humano en los fenómenos sociales y económicos (Amodio \& Keysers, 2018).

Desde un punto de vista socioeconómico, más allá del capitalismo y el Homo Economicus, corrientes francesas e inglesas sitúan el Homo Cooperativus en el centro de la economía social solidaria (Daudi \& Sotto, 1986; Lacroix, 2001). Así, para Ana Kasperowicz (2012), los rasgos diferenciales del Homo Cooperativus son las habilidades para la cooperación y la empatía. También, hay propuestas que plantean orientar la economía hacia modelos económicos que respeten el bienestar de todas las personas y los límites biofísicos del planeta. Modelos económicos guiados por personas más cooperadoras, más pro-sociales, como Homo Heuristicus, Homo Reciprocans, Homo Altruisticus o Homo Socialis, y teniendo en cuenta otros y diferentes modelos económicos (Raworth, 2018). Sin embargo, la cooperación no es una tarea fácil, porque exige interactuar con los demás en la práctica y requiere habilidades sociales y cognitivas, para conectar con los demás, necesitando en todo caso de una escucha activa y empatía (Sennett, 2012).

Igualmente, se identifican dos variables que pueden ser importantes a la hora de investigar los elementos de persona y cooperación: el género (y sexo) y la edad. En cuanto al género, Denise Anthony y Christine Horne (2003) manifiestan que algunos estudios encuentran a las mujeres más cooperadoras que a los hombres; otros en cambio, expresan que no es el género en sí mismo lo que afecta el comportamiento. Así, analizan por un lado el efecto de los valores interiorizados; y, por otro lado, la composición del género y el efecto de las expectativas. Está más justificada en cambio, la influencia de la edad a la hora de cooperar.

Desde la perspectiva de la psicología evolutiva, por ejemplo, Piaget explicita diferentes etapas cognitivas evolutivas. Bandura, con perspectiva cognitivo social, da importancia a los procesos mentales internos y a la interacción del sujeto con los demás; y a la autoeficacia como confianza en la competencia personal. Para Vigotsky el aprendizaje sociocultural de cada individuo es un mecanismo fundamental de desarrollo, y la cooperación es una variable necesaria para lograr el nivel evolutivo potencial. Al fin y al cabo, desde que 
nacemos tenemos que cooperar con los adultos comenzando la adaptación de nuestra capacidad de cooperación. Así, Erikson hace énfasis en que nos desarrollamos a través de la cooperación, obteniendo la capacidad de participar en interacciones cada vez más complejas. Esto da como resultado el desarrollo de la autoconciencia mediante la experimentación y la comunicación. A medida que envejecemos, se vuelven más importantes, especialmente las habilidades de comunicación para construir relaciones, y poder así cooperar (Cantero, Pérez y Navarro, 2011; Sennett, 2012).

Todas estas perspectivas y ópticas han influido históricamente en diferentes corrientes pedagógicas y metodologías educativas que han contribuido en facilitar experiencias, contextos e interacciones de enseñanza-aprendizaje para el desarrollo integral de personas y comunidades más democráticas. Desde finales del siglo XIX se han implementado pedagogías cooperativas mediante, por ejemplo, la Escuela Nueva o Activa y la Escuela moderna. Practicas pedagógicas, en sus momentos fueron transformadoras, inspiradas en Rousseau y sus seguidores Pestalozzi y Fröbel, y desarrolladas posteriormente por Decroly, Montessori, Neill, Freinet y Dewey, entre muchos otros. También, cabe mencionar que la colaboración y la cooperación en educación se expresa mediante formas de aprendizaje como el aprendizaje colaborativo, el aprendizaje cooperativo o el aprendizaje complejo (Armijo, 2018).

\subsection{Revisión de la Persona Cooperativa en el ecosistema cooperativista vasco}

Si bien es cierto que no hemos encontrado teorías que sustenten una definición fundamentada del concepto de la Persona Cooperativa, para contextualizar la investigación en el ecosistema cooperativista del País Vasco, cabe mencionar, el pensamiento filosófico de su inspirador José María Arizmendiarrieta. En este sentido, Larraitz Altuna (2008) explica el desarrollo de la teoría del ser humano y la comunidad de Arizmendiarrieta, centrada en un enfoque humanista y partiendo del pensamiento personalista de los filósofos franceses J. Maritain y E. Mounier. El pensamiento distingue muy bien al individuo (ser físico) y la persona (ser moral) y subraya el auto empoderamiento basado en la (auto)conciencia como clave para la autorrealización de las personas y las comunidades. El ser humano se desarrolla en, y con la comunidad; calificando como indivisibles las transformaciones de las personas y las transformaciones sociales. Caracteriza la persona como digna, libre, madura, creativa, idealista-práctica y comunitaria. Que ésta sea responsable: participativa y con principios morales. Constructora de sí misma: transformadora, trabajadora y auto-realizada. Utópica, vital para los desarrollos individuales y comunitarios: emprendedora, activa e idealista práctica. Estas líneas de pensamiento de Arizmendiarrieta, tratadas por Joxe Azurmendi (1984), son cercanas a la conceptualización que Georges Lasserre (1980) desarrolla sobre el Hombre Cooperativo.

\section{Proyectos para la trasformación educativa y social en el contexto vasco}

Con la intención de responder a los desafíos de las personas y las comunidades, cada vez son más las escuelas y las facultades universitarias que desarrollan programas para transformar los modelos educativos basados en marcos pedagógicos centrados en el desarrollo integral de la persona. Algunas de esas experiencias también se están realizando en el País Vasco.

Entre ellas se puede mencionar, por ejemplo, el sistema Amara Berri (Anaut, 2004) que tienen como objetivo desarrollar un ser global con su personalidad, sus relaciones sociales y sus aprendizajes. Este sistema se basa en una concepción del alumnado como un ser global con sus propias motivaciones e intereses, con unos esquemas conceptuales y emocionales determinados y con un potencial propio e individual (Karrera y Arguiñano, 2018). Por otro lado, Antzuola Herri Eskola es otro ejemplo de modelo pedagógico cuyos pilares son tanto el bienestar como el desarrollo integral de los niños, el desarrollo profesional del colectivo escolar y la integración de la escuela en el contexto natural, social y cultural en el que se ubica (Arregi, 2015).

A su vez, pueden encontrarse trasformaciones que se están realizando en las escuelas y facultades de enseñanza cooperativa (constituidas como entidades jurídicas y societarias), las cuales evolucionan mediante cambios, tanto pedagógicos, metodológicos, arquitectónicos, como personales. En el caso de las Ikastolas, son cada vez más las que basan su transformación educativa en la Pedagogía de la confianza (Antero, 2015). Esta propuesta tiene como objetivo el desarrollo de la persona en su integridad, facilitando para ello contextos y experiencias de confianza, bienestar y seguridad para así construir la auto-confianza, la confianza en los demás y confianza en el entorno.

En el caso de la universidad cooperativa de Mondragon Unibertsitatea, cada facultad progresa mediante transformaciones educativas orientadas por el marco pedagógico Mendeberri 2025 (García, Zubizarreta y Astigarraga, 2017). Un modelo educativo basado en el desarrollo personal (humano y ciudadano) y profesional de la comunidad educativa, donde se identifican 6 ejes que sustentan el modelo: ciudadano del mundo, identidad y objetivos personales, aprendiz flexible, aprendiz activo, comunicador y facilitador de comunicación y, por último, cooperativo. 
En todos estos procesos relatados se re-define la misión educativa de cada centro relacionándola con el perfil de persona (perfil del alumnado) que se quiere desarrollar. De este modo, al iniciar a determinar dichos perfiles es cuando se identifica la necesidad de definir y caracterizar el perfil de Persona Cooperativa para poder identificar las claves de su desarrollo y poder así evaluarlo o medirlo. Sin embargo, la revisión bibliográfica realizada en las principales bases de datos (WOS, Scopus...) no ha aportado una clara definición ni caracterización del perfil. Por ello, estudios como el presente pueden permitir establecer bases teóricas de este concepto que, con posterioridad, permitan el desarrollo de instrumentos para su medición y evaluación. En esta sociedad donde cada vez la individualización es también globalizada, puede ser importante identificar un perfil más humano y más democrático, donde los valores y actitudes cooperativas desempeñen un rol imprescindible para favorecer una evolución (cooperativa y comunitaria) del ser humano en clave de transformación social. Somos conscientes de que, también en este objetivo, la Educación juega un papel determinante.

\section{Objetivos}

El objetivo de esta investigación es definir y caracterizar el perfil de "Persona Cooperativa" desde una perspectiva educativa. Entendemos que, la falta de una definición fundamentada del concepto de estudio hace necesaria y oportuna una investigación que permita extraer sus rasgos y características principales, que ello pueda ayudar al fomento de esos valores y comportamientos y, en última instancia, poder evaluar la medida en la que los programas educativos puedan incidir en el desarrollo de todos ellos.

\section{Método}

\subsection{Enfoque metodológico}

La metodología utilizada con objeto de alcanzar el objetivo propuesto ha sido la Teoría Fundamentada (Grounded Theory) dado que es un método de investigación para la recogida y análisis de los datos cualitativos, que permite generar una teoría desde los datos que ofrece el contexto (Glaser \& Strauss, 1967). Este método basado en la exploración, permite enfatizar tanto los incidentes como las diferentes condiciones que afectan la creación y el desarrollo de una teoría (Strauss, 1987). Por lo tanto, y para dar respuesta a los objetivos de este trabajo, se presenta el diseño y desarrollo del estudio realizado adaptando la propuesta de Antonio Trinidad, Virginia Carrero y Rosa M. Soriano (2006).

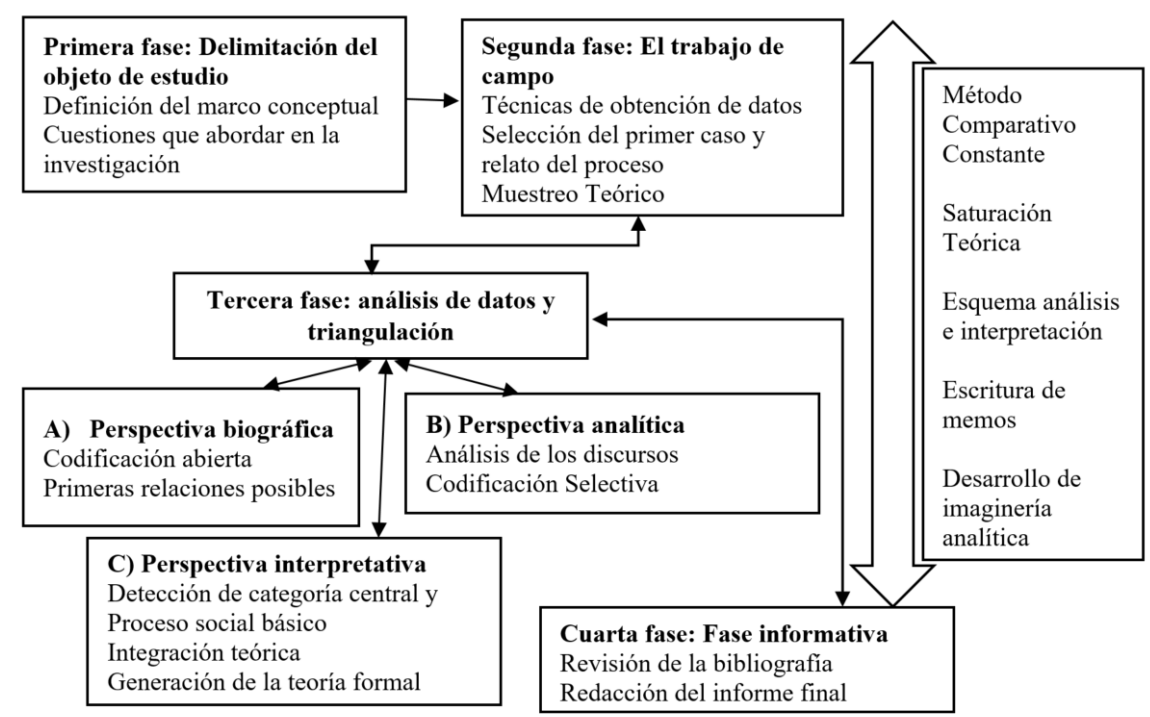

Figura. 1. Diseño de la investigación. Adaptada de Trinidad, Carrero y Soriano (2006:129).

Del mismo modo, en el diseño se tiene en cuenta, por un lado, el muestreo teórico (Trinidad, Carrero y Soriano, 2006) limitando la muestra dentro de las instituciones educativas, facultades universitarias y empresas vinculadas al ámbito educativo cooperativo y dentro del ecosistema cooperativista del País Vasco. De esta manera, los participantes son seleccionados dependiendo de las expectativas que generan de aportación de nuevas ideas en relación con la teoría que se está desarrollando. Por otro lado, se considera la 
discusión existente sobre la saturación teórica (Saunders et al., 2017). A la hora de aplicar la Teoría Fundamentada es importante definir claramente desde el diseño qué es la saturación teórica, dónde y por qué se produce, y cuándo y cómo se decide. Por ello, nos propusimos buscar una mayor observación para aumentar el grado de inmersión, buscar una comprensión más profunda más allá de la saturación y completar los posibles vacíos que pudieran existir en los datos.

\subsection{Participantes, instrumentos y proceso de obtención de datos}

Después de haber abordado hasta el momento la primera fase de estudio, la delimitación del objeto de estudio, se procede al desarrollo del trabajo en el campo. En esta segunda fase, la recogida de datos se realizó entre diciembre del 2017 y mayo del 2018 con la participación de 36 personas. Para ello se emplearon tres técnicas diferenciadas: entrevistas semiestructuradas con guion semiabierto (Taylor y Bogdan, 1987), observación panorámica no participante (Ruiz, 1999) y análisis de documentación interna (con comparación constante). Los datos obtenidos fueron confidenciales y fueron grabados y transcritos para su mejor procesamiento. En el proceso de recogida, análisis y publicación de los datos se tuvieron cuenta en los aspectos éticos que requiere una investigación, los participantes han facilitado su aprobación para ello (consentimiento informado). En la siguiente Tabla 1 se presenta la información de la recogida de datos en el orden temporal de la investigación.

Tabla. 1. Recogida de datos: participantes, instrumentos y proceso de obtención de datos. *ES: Entrevista semiestructurada; ADI: Análisis de documentos internos OPNP: Observación panorámica no participativa.

\begin{tabular}{|c|c|c|}
\hline $\begin{array}{l}\text { Instrumentos y } \\
\text { datos }\end{array}$ & Características & Motivos de selección \\
\hline $\begin{array}{l}\text { ES. Gerente } \\
\text { Arizmendi } \\
\text { Ikastola. }\end{array}$ & $\begin{array}{l}\text { Cooperativa educativa integral, } \\
\text { Centro educativo, comarca Alto- } \\
\text { Deba (Gipuzkoa). }\end{array}$ & $\begin{array}{l}\text { Selección primer caso, Ikastola de } \\
\text { antecedentes de investigación, análisis del } \\
\text { perfil de salida de PC }\end{array}$ \\
\hline $\begin{array}{l}\text { ES. Gerente San } \\
\text { Fermín Ikastola. }\end{array}$ & $\begin{array}{l}\text { Cooperativa de familias, Centro } \\
\text { educativo, Pamplona. }\end{array}$ & $\begin{array}{l}\text { Situada en otra provincia y otro contexto } \\
\text { económico no cooperativista, Análisis de } \\
\text { los perfiles de salida y el perfil de PC. }\end{array}$ \\
\hline $\begin{array}{l}\text { ADI. Mondragon } \\
\text { Unibertsitatea. }\end{array}$ & $\begin{array}{l}\text { Universidad cooperativa, situada en } \\
\text { la comarca de Alto-Deba y fuera de } \\
\text { ella. }\end{array}$ & $\begin{array}{l}\text { Análisis del perfil de PC y los perfiles de } \\
\text { salida del alumnado de la Universidad y } \\
\text { Formación Profesional. }\end{array}$ \\
\hline $\begin{array}{l}\text { ES. Responsable } \\
\text { personal Orkli S. } \\
\text { Coop. }\end{array}$ & $\begin{array}{l}\text { Empresa cooperativa, Ordizia } \\
\text { (Gipuzkoa). }\end{array}$ & $\begin{array}{l}\text { Analizar las similitudes y diferencias } \\
\text { entre el perfil de PC y el perfil de los } \\
\text { trabajadores en un contexto } \\
\text { cooperativista externo del Alto-Deba. }\end{array}$ \\
\hline $\begin{array}{l}\text { ADI. HUHEZI, } \\
\text { MU. }\end{array}$ & $\begin{array}{l}\text { Facultad de la Universidad } \\
\text { cooperativa, comarca de Alto-Deba. }\end{array}$ & $\begin{array}{l}\text { Contrastar la definición y caracterización } \\
\text { de la PC. }\end{array}$ \\
\hline $\begin{array}{l}\text { OPNP. ULMA } \\
\text { UHS. }\end{array}$ & $\begin{array}{l}\text { Empresa cooperativa, Oñati } \\
\text { (Gipuzkoa); sesiones formativas } \\
\text { guiados por el instituto de estudios } \\
\text { cooperativos LANKI, MU. }\end{array}$ & $\begin{array}{l}\text { Analizar si hay nuevos conceptos en los } \\
\text { discursos de } 30 \text { trabajadores en un } \\
\text { contexto más amplio, se analizan } 14 \\
\text { sesiones en las cuales se trabajaban } \\
\text { valores y actitudes cooperativas. }\end{array}$ \\
\hline $\begin{array}{l}\text { ADI y contraste } \\
\text { Instituto de } \\
\text { estudios } \\
\text { cooperativos } \\
\text { LANKI. }\end{array}$ & $\begin{array}{l}\text { Instituto de estudios cooperativos } \\
\text { de MU, Facultad cooperativa, } \\
\text { Comarca Alto-Deba. }\end{array}$ & $\begin{array}{l}\text { Analizar la definición y caracterización } \\
\text { de la PC, y contrastar datos con } 2 \\
\text { investigadores del instituto de estudios. }\end{array}$ \\
\hline $\begin{array}{l}\text { ES. Presidente } \\
\text { Grupo ULMA. } \\
\text { UHS. }\end{array}$ & $\begin{array}{l}\text { Empresa cooperativa, } \\
\text { (Gipuzkoa). }\end{array}$ & $\begin{array}{l}\text { Analizar las similitudes y diferencias } \\
\text { entre el perfil de salida de PC y el perfil } \\
\text { de los trabajadores en un contexto } \\
\text { cooperativista del Alto-Deba. }\end{array}$ \\
\hline
\end{tabular}

Fuente: Elaboración propia.

La investigación comenzó trabajando las muestras con actitud flexible y con perspectiva abierta y relativamente desenfocada para favorecer las necesidades de la teoría que emergía (Trinidad, Carrero y Soriano, 2006). Por ello, después de analizar los datos recogidos en la primera entrevista se decidió entrevistar a la directora de una cooperativa educativa que no pertenecía al Grupo Mondragón y que se encontraba en un contexto económico no cooperativista. Las categorías y los códigos que se identificaron fueron similares, y aunque en algunos casos la terminología fue diferente, la comprensión fue similar. Se 
planteó la necesidad de ampliar el ámbito de la investigación, seleccionando la recogida y análisis de documentos a nivel universitario. Por otro lado, se decidió efectuar otra entrevista en un entorno laboral. La selección se realizó teniendo en cuenta el carácter cooperativo de la empresa y el carácter externo de la comarca. En comparación con las cooperativas de educación aparecieron nuevos elementos relacionados con el mundo laboral, y los valores y actitudes cooperativos comenzaron a adquirir un gran peso en la caracterización de la Persona Cooperativa.

Para seguir comparando constantemente se consideró necesario contrastar los datos obtenidos con los datos generales de Mondragon Unibertsitatea y los documentos internos de la Facultad de Humanidades y Ciencias de la Educación (HUHEZI): para trabajar la comprensión conceptual e iniciar a determinar la construcción de relaciones. A continuación, se consideró interesante ampliar el ámbito de análisis. Es decir, hasta este punto se desarrolló la investigación con directores y documentos oficiales de las instituciones, por lo que se optó por realizar observaciones panorámicas no participantes en el proceso interno de una empresa cooperativa. En consecuencia, los datos comenzaron a ser repetitivos y se observó que estaba cerca la saturación teórica. Aun así, las relaciones entre categorías y códigos no se consideraron definitivas.

Para finalizar el proceso de obtención de datos se buscó confrontar la información. Para ello que se recurrió primero al Instituto de estudios cooperativos LANKI (Mondragon Unibertsitatea) donde se realizó un contraste del análisis construido y se confirmaron así las relaciones entre conceptos. Asimismo, se analizaron documentos internos del Instituto de estudios. Este paso fue importante para confirmar la creación de la Categoría Central y los procesos sociales básicos. Después de constatar la teoría emergente se efectuó una última entrevista. De este modo, tras realizar una valoración en el grupo de investigación, se decidió que la investigación había llegado a la Saturación Teórica. Una vez llegados a ésta se revisaron de nuevo todos los datos recolectados.

\subsection{Análisis y triangulación de datos}

Basados en la Teoría Fundamentada, y tras el proceso de recogida de datos se ha realizado el análisis y la triangulación mediante el método comparativo constante hasta lograr la saturación teórica. En esta tercera fase, se han practicado trabajos de contraste y comparación con un grupo de investigadores/as de carácter multidisciplinar: 1 doctor en Psicología y experto en emociones y Psicología de grupos, 1 doctor en Psicodidáctica, 1 doctora en Ingeniería organizacional, 1 doctor en Filosofía y 4 investigadores de ámbito de Educación, Cooperativismo, Biología, Ciencias políticas e Ingeniería organizacional.

Tal y como recomiendan Trinidad, Carrero y Soriano (2006) los datos extraídos en la recogida de datos se han analizado hasta lograr la saturación teórica, es decir, hasta el momento en que se ha entendido y observado que la información es repetitiva y suficiente para cumplir los objetivos. La perspectiva biográfica comienza con la codificación abierta, dividiendo los datos para trabajar diferentes categorías y propiedades. Este proceso ha permitido conocer el camino a seguir en la investigación identificando los incidentes, creando y comparando las categorías, pudiendo visualizar así las primeras posibles conexiones entre ellas. El proceso sigue con la perspectiva analítica, donde se analizan los datos mediante la codificación selectiva, haciendo posible la reducción de datos. De esta manera, emergen tanto las categorías como las relaciones entre ellas, visualizando el núcleo de la teoría emergente y concibiendo la Categoría Central. Este paso, propone nuevas preguntas que profundizan el esquema inicial de análisis e interpretación de datos, necesaria esta para definir las categorías y las relaciones entre ellas, ayudado por la escritura de memos. En este caso, los valores y las actitudes comienzan a coger fuerza y a relacionarse con el perfil de Persona Cooperativa. Finalmente, el proceso concluye desde una perspectiva interpretativa y una codificación teórica. En este momento, habiendo alcanzado la saturación de la información y la estabilidad de las categorías y códigos, para profundizar y asegurar la saturación teórica, se decide buscar mayor rigurosidad, una comprensión más profunda, para aumentar el grado de inmersión (Saunders et al., 2017). Así, se construye el último modelo de esquema para el análisis e interpretación y, en consecuencia, la Categoría Central. Esta Categoría Central es el código central que explica y da sentido a todos los datos y sus relaciones, explicando así una mayor variabilidad en el patrón de comportamiento social objeto de estudio. Una vez confirmada la saturación teórica se revisan de nuevo todos los datos recolectados. De esta manera, se definen tres procesos sociales básicos, los cuales ayudan a determinar lo que es genérico, permitiendo una caracterización sustantiva. Y se construye la teoría formal para ser contrastada y fortalecida con la revisión bibliográfica.

\section{Resultados}

A continuación, se presentan los resultados obtenidos en la tercera fase de estudio, los cuales se han extraído de los datos recopilados mediante las entrevistas, observaciones panorámicas no participantes y análisis de documentos internos; considerando, igualmente, la perspectiva teórica elaborada en el artículo. El proceso de contraste y de elaboración de resultados se ha sustentado en el modelo de Trinidad, Carrero y Soriano 
(2006). Cabe mencionar que el análisis del contenido de tales datos ha sido examinado y contrastado por un equipo de investigación de carácter multidisciplinar compuesto por 8 investigadores/as. Así, los resultados emergen desde el análisis, la interpretación y la organización de discursos, ideas y conceptos que se han realizado mediante la construcción y el uso del esquema para el análisis e interpretación de los discursos articulados, que se presenta seguidamente (Figura 2). De esta forma, partiendo de las preguntas de investigación iniciales, ¿qué es la Persona Cooperativa? y ¿qué la define y caracteriza?, se han generado nuevas preguntas e hipótesis, originadas todas ellas por el método de comparación constante.

El empleo de este esquema, elaborado en el desarrollo de la Teoría Fundamentada, ha facilitado los siguientes resultados que se formulan posteriormente: el mapa de categorías y códigos principales (Figura 3), la creación de la Categoría Central (Tabla 2) y la descripción del informe final de la teoría formal marcados por el objetivo planteado. Esto es, se expone la elaboración tanto de la definición como de la caracterización del perfil de Persona Cooperativa.

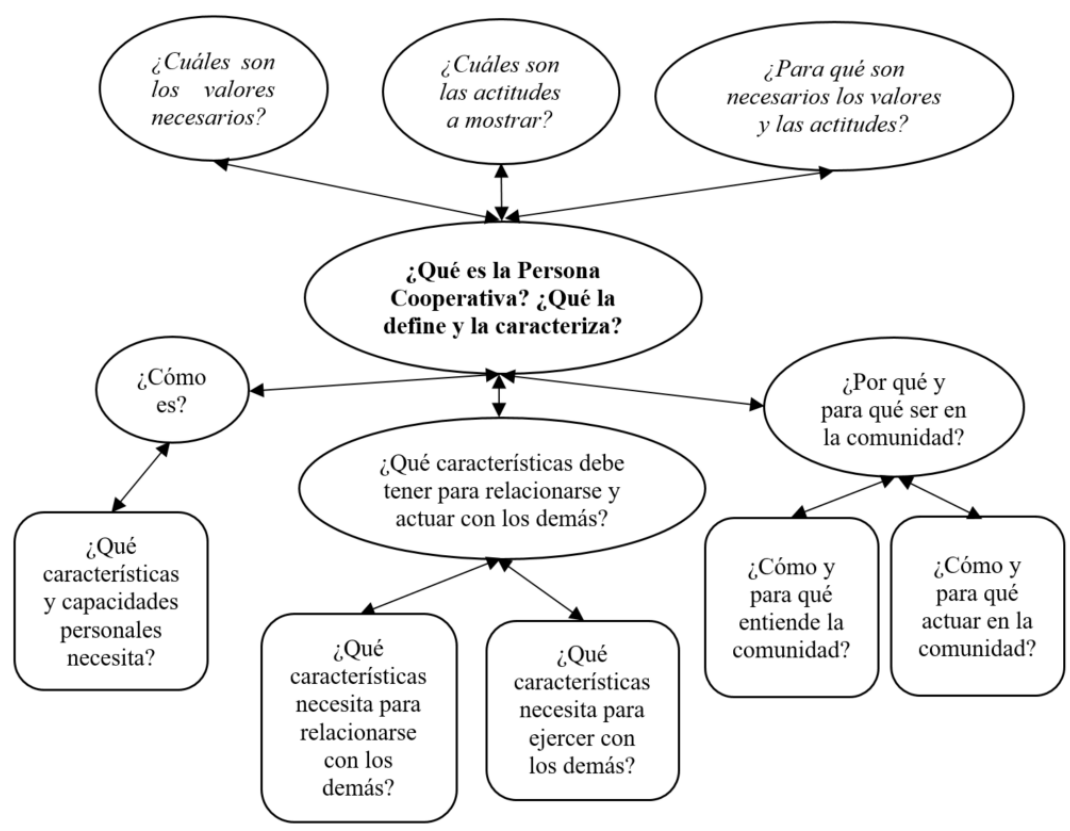

Figura. 2. Esquema para el análisis e interpretación de los discursos articulados.

El desarrollo y uso de este esquema ha permitido, como primer resultado, la construcción del mapa de categorías y códigos principales, importante para poder generar y ordenar las relaciones y comprensiones entre categorías y conceptos.

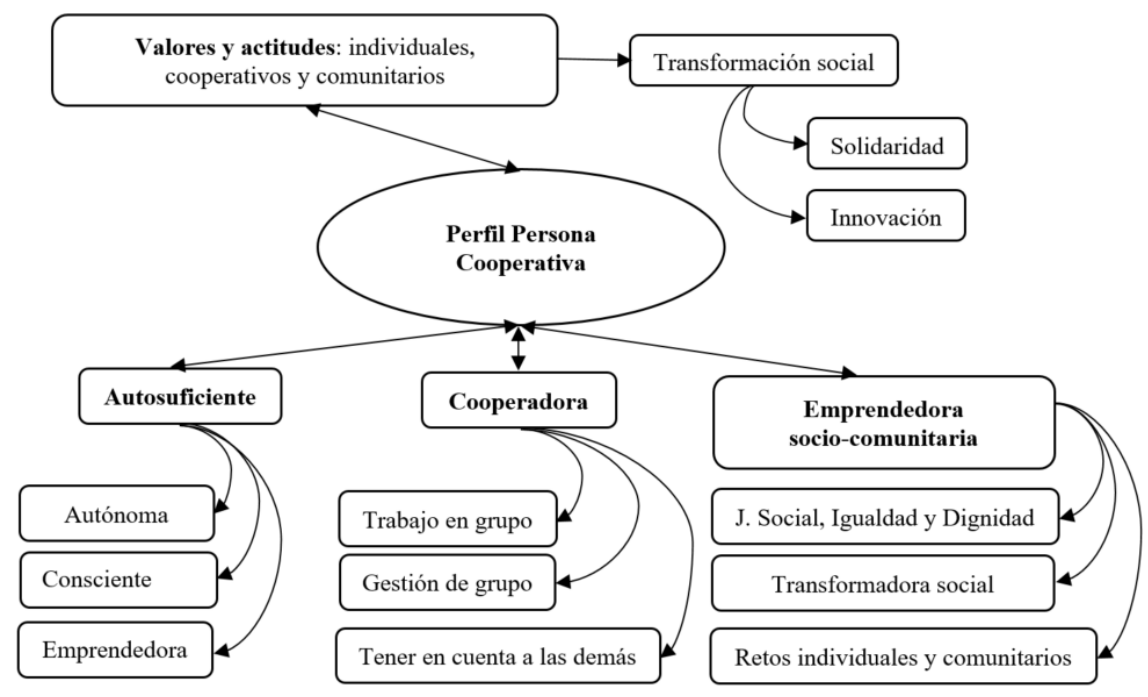

Figura. 3. Mapa de categorías y códigos principales. 
Asimismo, el empleo del esquema y mapa presentados han hecho posible la creación de la Categoría Central. En la siguiente Tabla 2 se detallan los resultados obtenidos en la creación de la Categoría Central, los cuales organizan, explican y dan sentido a los procesos sociales básicos, conceptuales y sustantivos generados.

Tabla. 2. Creación de la Categoría Central.

\begin{tabular}{|c|c|c|c|}
\hline Sustantivos & Conceptuales & $\begin{array}{l}\text { Procesos } \\
\text { Sociales } \\
\text { Básicos }\end{array}$ & $\begin{array}{l}\text { Categoría } \\
\text { Central }\end{array}$ \\
\hline $\begin{array}{l}\text { 1. Es persona autónoma: } \\
\text { 1.1. Es capaz de auto-organizarse/ auto-gestionarse, sabe hacer } \\
\text { y sabe aprender } \\
\text { 1.2. Tiene autoestima: confianza en sí misma } \\
\text { 1.3. Tiene conocimiento de sí misma y gestiona sus emociones } \\
\text { 1.4. Se cuida, es saludable. } \\
\text { 2. Es persona consciente: } \\
\text { 2.1. Tiene un punto de vista humano y ético, moral. } \\
\text { 2.2. Es capaz de tomar decisiones y responder a ellas: } \\
\text { responsable, crítico y reflexivo. } \\
\text { 3. Es persona emprendedora: } \\
\text { 3.1. Es participativa: activa, con iniciativa, motivada y } \\
\text { comprometida. } \\
\text { 3.2. Es innovadora (permanente, resiliente) y creativa. }\end{array}$ & $\begin{array}{l}\text { ¿Cómo es? } \\
\text { Autosuficiente } \\
\text { "Saber ser y } \\
\text { sabe aprender } \\
\text { para ello" }\end{array}$ & $\begin{array}{l}\text { Eje personal } \\
\text { Intrapersonal }\end{array}$ & $\begin{array}{l}\text { Valores y } \\
\text { actitudes } \\
\text { individuales, } \\
\text { cooperativos } \\
\text { y } \\
\text { comunitarios } \\
\text { "Necesarios } \\
\text { para la } \\
\text { transformaci } \\
\text { ón social } \\
\text { basada en la } \\
\text { solidaridad y } \\
\text { la } \\
\text { innovación" }\end{array}$ \\
\hline $\begin{array}{l}\text { 4. Actúa en grupos de trabajo: } \\
\text { 4.1. Es capaz de trabajar, colaborar y cooperar en grupos. } \\
\text { 4.2. Trabaja para sí misma y para las demás (objetivos } \\
\text { compartidos). } \\
\text { 4.3. Comprometida, coge compromisos. } \\
\text { 5. Influye positivamente en la gestión del grupo: } \\
\text { 5.1. Tiene impacto positivo en el grupo } \\
\text { 5.2. Tiene influencia positiva en el liderazgo } \\
\text { 5.3. Es capaz de tomar decisiones con las demás. } \\
\text { 5.4. Confía en las demás. } \\
\text { 6. Es capaz de relacionarse de forma correcta y saludable } \\
\text { con las demás: } \\
\text { 6.1. Es capaz de entender a las demás: empatía, lástima. } \\
\text { 6.2. Entiende las emociones de las demás. } \\
\text { 6.3. Toma en cuenta la realidad de las demás y la respeta. } \\
\text { 6.4. Es constructora de comunicaciones positivas: sabe } \\
\text { escuchar activamente y es asertiva }\end{array}$ & $\begin{array}{l}\text { ¿Qué } \\
\text { características } \\
\text { debe tener para } \\
\text { relacionarse y } \\
\text { actuar con las } \\
\text { demás? } \\
\text { Ejerce la } \\
\text { cooperación } \\
\text { "Sabe actuar } \\
\text { con las demás y } \\
\text { construir } \\
\text { relaciones } \\
\text { positivas" }\end{array}$ & $\begin{array}{l}\text { Eje } \\
\text { relacional } \\
\text { Interpersonal }\end{array}$ & \\
\hline $\begin{array}{l}\text { 7. Piensa y ejerce para la justicia social, la igualdad de } \\
\text { oportunidades y en la dignidad de todas las personas: } \\
\text { 7.1. Practica la solidaridad generosamente. } \\
\text { 7.2. Busca el bienestar individual y colectivo } \\
\text { 7.3. Es igualitaria e inclusiva. } \\
\text { 8. Tiene conciencia emprendedora para la transformación } \\
\text { social: } \\
\text { 8.1. Es emprendedora social, activa social, participante social. } \\
\text { 8.2. Es innovadora social y trabaja con y para la } \\
\text { transformación social solidaria: juntas y para todas. } \\
\text { 8.3. Tiene compromiso social (sociedad más auto-organizada/ } \\
\text { auto-gestionada) ejerciendo solidaridad económica, social, } \\
\text { ecológica y cultural. } \\
\text { 9. Trabaja para responder a los retos individuales y } \\
\text { comunitarios del siglo XXI: } \\
\text { 9.1. Está vinculada, arraigada, a la comunidad (al contexto) y } \\
\text { participa en ella: y es abierta al mundo. } \\
\text { 9.2. Tiene una actitud abierta hacia la cultura vasca (y otras } \\
\text { culturas) y la lengua vasca (euskara): la cual lo utiliza y/o la } \\
\text { promueve. } \\
\text { 9.3. Tiene perspectiva de futuro: hacia el planeta, los proyectos }\end{array}$ & $\begin{array}{l}\text { ¿Por qué y para } \\
\text { qué ser en la } \\
\text { comunidad? } \\
\text { Emprendedora } \\
\text { socio- } \\
\text { comunitaria } \\
\text { "Sabe pensar y } \\
\text { ejercer por y } \\
\text { para la } \\
\text { transformación } \\
\text { social" }\end{array}$ & $\begin{array}{l}\text { Eje socio- } \\
\text { comunitaria } \\
\text { Transpersona } \\
1\end{array}$ & \\
\hline
\end{tabular}


individuales y comunitarios (sentido del legado)

9.4. Tiene confianza en la comunidad

Fuente: Elaboración propia

Esta creación de la Categoría Central ha habilitado la descripción final de la teoría formal. Esto es, ha permitido definir y caracterizar el perfil de Persona Cooperativa.

De los resultados obtenidos puede extraerse que, por una parte, la centralidad del perfil de Persona Cooperativa está constituida por los valores y actitudes individuales, cooperativos y comunitarios que tienen en cuenta al ser humano y a la sociedad. Por otra parte, se identifican y definen los tres procesos sociales básicos, y las categorías conceptuales y sustantivas que lo definen y caracterizan. Todas estas categorías, interrelacionados entre sí, se consideran necesarias para pensar y realizar una transformación social basada en la solidaridad y la innovación. Donde la solidaridad se entiende en clave de pensamiento y acción (participación social-comunitaria) para hacer efectiva la justicia social, la igualdad de oportunidades y la dignidad de todas las personas; y la innovación se define como la creatividad permanente para la autogestión/ auto-organización personal, organizacional y comunitaria, y para la inter-cooperación entre personas y grupos (organizaciones, instituciones, asociaciones...).

De esta forma, el resultado de la definición de Persona Cooperativa se sintetiza de la siguiente manera:

Persona Cooperativa es aquella que posee valores y actitudes individuales, cooperativos y comunitarios que tienen en cuenta al ser humano y a la sociedad. Es autosuficiente, ejerce la cooperación y es emprendedora socio-comunitaria, pensando y trabajando por y para la transformación social basada en la solidaridad y la innovación.

A su vez, los valores y actitudes individuales, cooperativos y comunitarios identificados en el estudio son los siguientes:

Generosidad, solidaridad, trabajo en común, participación, justicia social, igualdad de oportunidades, dignidad, democracia, equidad, transparencia, respeto, lealtad, humildad, igualdad, libertad, honestidad, diversidad, bienestar, confianza, responsabilidad social, innovación social, emprendimiento social, cooperación y compromiso social...

Por lo tanto, los valores y actitudes individuales, cooperativos y comunitarios representan la centralidad de la definición, caracterización y orientación del perfil de la Persona Cooperativa; y guían su pensamiento y su comportamiento. La clave se encuentra en el uso de éstos como, por ejemplo, a la hora de tomar decisiones individuales y colectivas, trabajar en equipo y/o entre grupos, desarrollar relaciones, orientar cambios y/o construir una misión y visión socio-comunitaria para responder tanto a los retos individuales, organizacionales como a los comunitarios.

Finalmente, se alcanzan los resultados que caracterizan el perfil de Persona Cooperativa en tres ejes principales: el personal, el relacional y el social-comunitario. El primer eje, la dimensión personal, responde a cómo es la persona, a sus aspectos (competencias, habilidades, valores y actitudes) intrapersonales. La categoría de autosuficiente se refiere a que la persona sabe ser y sabe auto-realizarse para ello (sabe aprender para ello). Esta categoría se compone de los tres rasgos siguientes: autónoma, consciente y emprendedora. La autonomía se relaciona con la capacidad de auto-organización, autogestión, autoestima, autoconocimiento, gestión de emociones y cuidado personal. El ser consciente involucra el tener un punto de vista humano y ético (moral) a la hora de tomar decisiones y responder a ellas, actuando con responsabilidad, criterio y reflexionando sobre ellas. El tercer rasgo, el ser emprendedora, hace referencia a ser una persona participativa-activa e innovadora permanente, siendo importante para ello la creatividad.

El segundo eje repara en la dimensión relacional, en los aspectos interpersonales. De este modo, la categoría de ejercer la cooperación hace referencia al cómo se relaciona e interactúa positivamente la persona con las demás a la hora de cooperar. Esta categoría integra los siguientes tres rasgos: trabajo en grupo, gestión de grupo y tener en cuenta a las demás. El trabajo en grupo implica saber trabajar cooperando con las demás, ser capaz de establecer objetivos compartidos (individuales y colectivos) y comprometerse con ellos. De la misma manera, debe influir positivamente en el grupo y en el liderazgo, siendo capaz de tomar decisiones con las demás y contribuir a generar un clima de confianza grupal. Tener en cuenta a las demás supone saber relacionarse de forma correcta y saludable. Interiorizar conciencia hacia las demás. Esto es, ser persona empática a la hora de entender las realidades y emociones de las demás y respetarlas. Así, se califica como importante ser constructora de comunicaciones positivas, esto es, relacionarse con escucha activa y asertividad.

Por último, el tercer eje hace hincapié en la orientación social-comunitaria, en los aspectos transpersonales. De este modo, se especifica el por qué y el para qué ser y hacer en la comunidad, un querer transformar; esto es, al rol que juega la persona en y con la comunidad. Esta categoría se constituye de los siguientes tres rasgos: justicia social, igualdad de oportunidad y dignidad de las personas; transformadora social; y retos individuales y comunitarios. El primer rasgo, se refiere tanto al pensamiento como a la acción para obtener una comunidad más justa socialmente, haciendo viable la igualdad de oportunidades y dignidad 
para todas las personas. Reclama buscar el bienestar individual y colectivo desde la igualdad y la inclusividad. El ser transformadora social implica tener conciencia social, siendo emprendedora social y participativa-activa social. Requiere ser innovadora social para poder así trabajar por y para una transformación social solidaria: cooperar juntas y para todas. Esto es, involucra tener una mentalidad y práctica donde se trabaja en cooperación con otras personas de la comunidad (del propio grupo y/o con diferentes agentes, organizaciones, instituciones...) con el fin de que la evolución, los avances y/o beneficios de dichos procesos impacten en toda la comunidad. Para ello, se subraya la importancia de desarrollar una actitud solidaria y generosa hacia la inclusividad social. Esto, exige coger compromisos con fin de lograr una sociedad más auto-organizada/auto-gestionada ejerciendo solidaridad económica, social, ecológica y cultural. El último rasgo hace hincapié en trabajar para responder retos individuales y comunitarios del siglo XXI desde la innovación social solidaria y con mentalidad transformadora. De ahí la importancia de estar vinculada a la comunidad y participar en ella, estando abierta tanto a la cultura y lengua vasca como al mundo y otras culturas. También, se explicita el valor de tener perspectiva de futuro, poseer un sentido de legado hacia el planeta, la comunidad o proyectos individuales y colectivos. Todo ello, implica tener confianza en la comunidad.

\section{Discusión y conclusión}

Este estudio ha permitido definir y caracterizar el perfil de Persona Cooperativa en contextos escolares, universitarios y empresariales dentro del ámbito de enseñanza cooperativa y ecosistema cooperativista del País Vasco; con perspectiva educativa de aprendizaje para toda la vida y toda la comunidad. Se considera, también, la posibilidad de que el trabajo ofreciera un marco orientativo teórico y práctico para aquellos modelos educativos preocupados por situar el desarrollo integral o global de las personas en el centro de su actividad pedagógica y didáctica-metodológica. Siempre y cuando teniendo en cuenta la variada naturaleza de los modelos educativos actuales y las necesidades de cada sistema educativo.

A partir de los resultados de esta investigación en esta cuarta fase se concluye, por un lado, que el perfil de Persona Cooperativa podría interiorizar las competencias y habilidades necesarias que las personas necesitan adquirir y desarrollar para la vida en el siglo XXI, tanto para aprender y trabajar como para la ciudadanía (Wagner, 2012; National Research Council, 2012; Musicco, 2018). Las características identificadas se adecuan con los perfiles personales y profesionales necesarios y consensuados a nivel internacional (OCDE, 2015; 2019; World Economic Forum, 2016; Armijo, 2018; Anagün, 2018). Al fin y al cabo, el perfil de Persona Cooperativa ofrece la oportunidad de asociarla con diferentes saberes, por ejemplo: el saber ser, saber aprender a aprender, saber actuar, saber pensar, saber hacer, saber cooperar, saber relacionarse positivamente y saber/querer transformar; y se enlaza con la asunción de características como, entre otras, las siguientes: autogestión, autoeficacia, autoconciencia, creatividad, emprendizaje, interdependencia en el trabajo y gestión de grupo, asertividad, empatía, confianza y una visión de la vida humana solidaria, innovadora y transformadora social.

Por otro lado, los resultados podrían permitir determinar las claves para orientar su desarrollo y evaluación. En ese sentido, los valores y actitudes identificados han ayudado a revelar la importancia que los comportamientos humanos individuales, cooperativos y pro-sociales (-comunitarios) poseen en el perfil de Persona Cooperativa, las cuales podrían estar relacionadas con la necesidad de conseguir el equilibrio entre la persona y la comunidad: de atender los intereses personales y de actuar justos (De Waal, 2007). De este modo, cabría la posibilidad, por ejemplo, que la estructura de valores personales de Schwartz ayudara en la comprensión que juegan los valores en dichos comportamientos, ya que los valores individualistas no son independientes del todo de los valores colectivistas (Díaz, Díaz y González, 2017) y que los valores de la auto-transcendencia contribuyen a la creación de una mentalidad emocional y conductual relacionada con la empatía y la acción pro-social (Alessandri, Caprara, Eisenberg y Steca, 2009). Esta relación con el comportamiento pro-social podría ser importante porque se relaciona con las relaciones interpersonales positivas y el mantenimiento del bienestar personal y social. Incluso, cuenta con un efecto significativo en la competencia social a la hora de ayudar a construir relaciones humanas y resolver conflictos, o ayudar a prevenir el comportamiento antisocial (Lorente, Martí-Vilar y Puchol-Fraile, 2015; Martí-Vilar, Verdú-Ruiz y Serrano-Pastor, 2018; Martí-Vilar, Corell-Garcia, Merino-Soto, 2019).

Este estudio podría confluir, también, con otras investigaciones realizadas en contextos cooperativos y cooperativistas. Por ejemplo, otros trabajos realizados sitúan los valores detectados como básicos en diferentes experiencias de Educación Cooperativa (García, García y Figureas, 2018) y de Educación del cooperativismo (Inglada, Sastre y Villarroya, 2015), así como, junto a los principios cooperativos, necesarios para el desarrollo del modelo cooperativista (Moreno, 2017) y/o el éxito económico de empresas del modelo cooperativo (Cabaleiro, Iglesias y Martínez, 2019).

Igualmente, dicho perfil integra las características mencionadas del Homo Cooperativus (Kasperowicz, 2012) y podría estar en concordancia con los perfiles de personas más cooperadoras y pro-sociales 
mencionadas por Kate Raworth (2018). Situando a todas ellas en clave de respuesta a los diferentes retos del siglo XXI con perspectiva de desarrollo humano, social, económico, medioambiental (Puentes y Velasco, 2009) y cultural sostenible y responsable.

Incluso, los resultados observados en esta investigación se relacionan con el pensamiento filosófico del ser humano y la comunidad de Arizmendiarrieta (Azurmendi, 1984; Altuna, 2008) y las líneas de pensamiento del hombre cooperativo de Lasserre (1980). Porque, al fin y al cabo, la Persona Cooperativa integra una visión, una perspectiva o una forma de entender el ser humano en su entorno (comunidad). Esto nos lleva a comprender el concepto de Persona Cooperativa como persona integral. Por ello, la Persona Cooperativa no tiene por qué ser igual a persona cooperativista, aunque pueda ser necesaria, también, para el desarrollo del cooperativismo en el siglo XXI.

Para concluir, todas estas aportaciones podrían ayudar a la idea de poder seguir construyendo un modelo de Educación Cooperativa que desarrolle, también, Personas Cooperativas para la trasformación social.

\subsection{Futuras líneas}

En primer lugar, y a la luz de los resultados obtenidos resaltando que los valores y actitudes individuales, cooperativos y comunitarios representan la centralidad del perfil de la Persona Cooperativa, su pensamiento y su comportamiento resultaría necesario ahondar en un mayor conocimiento acerca de cómo se producen y desarrollan esas acciones como, por ejemplo, a la hora de tomar decisiones individuales y colectivas, en las formas de trabajar en equipo y/o entre grupos, las maneras de construir relaciones, prácticas de orientación al cambio y/o construcción de proyectos que permitan responder tanto a los retos individuales, organizacionales como comunitarios.

También, como futuras líneas de investigación, se identifica la necesidad de evaluar o medir sistemáticamente el progreso de los perfiles de las personas (Boletín Oficial del Estado, 2015; Severison, 2017; Aragay, 2017; Care et al., 2018; OCDE, 2019) y los comportamientos humanos cooperativos (Azurmendi, 2016), entre ellas la de Persona Cooperativa dentro de los ámbitos investigados. Entendemos que contar con una definición y caracterización del perfil de Persona Cooperativa robusto, puede permitir a las investigaciones futuras, elaborar un test fiable y valido para su medida (o evaluación). Así, el ámbito cooperativo educativo integral dispondría de una herramienta para examinar el desarrollo de la Persona Cooperativa.

Contar con un test de medida fiable y válido podría ayudar a los centros educativos a contar con un diagnóstico más en la orientación para innovaciones educativas. Así, los centros educativos tendrían la posibilidad de elaborar un diagnóstico continuo y sistemático del alumnado y observar el impacto que su actividad tiene en los valores y las actitudes recogidas en la caracterización de la Persona Cooperativa. Esta información podría ayudar a tomar decisiones asociadas a los diseños de los modelos educativos basadas en el desarrollo integral o global de la persona y que sirvan de referencia en el modelo de educación para los contextos complejos e inciertos del siglo XXI. Dicha medida se podría extrapolar a empresas y organizaciones las cuales estén interesadas en el desarrollo de dicho perfil en clave de formación continua. El test podría servir, de igual modo, para intentar identificar cuáles son los factores que favorecen la cooperación entre personas, e investigar las relaciones entre el individualismo y colectivismo o el egoísmo, la cooperación y el altruismo y verificar si hay grados que definan a la Persona Cooperativa. Con todo, ello podría ayudar a identificar y crear contextos y experiencias de aprendizaje para el desarrollo del perfil de Persona Cooperativa y de la cooperación entre personas en general.

Finalmente, dado que una de las limitaciones de esta investigación es que tanto el tipo de muestreo como la saturación teórica se encuentran dentro del ecosistema cooperativista del País Vasco, se considera interesante realizar contrastes en la definición y caracterización del perfil de Persona Cooperativa en otros contextos organizacionales y socioculturales de diferentes realidades con el fin de seguir alimentando el constructo de Persona Cooperativa. De este modo, para futuras investigaciones se puede considerar un diseño secuencial mixto exploratorio, mediante la apertura de nuevos criterios para la saturación teórica en otros contextos educativos y culturales.

\section{Referencias bibliográficas}

Adolphs, R. (2001) The neurobiology of social cognition. Current opinion in neurobiology, Vol. 2, No 11, pp. 231-239. DOI: $10.1016 /$ S0959-4388(00)00202-6.

Adolphs, R. (2003) Cognitive neuroscience: Cognitive neuroscience of human social behaviour. Nature Reviews Neuroscience, Vol. 3, № 4, pp. 165-178. DOI: 10.1038/nrn1056.

Alessandri, G., Caprara, G. V., Eisenberg, N. \& Steca, P. (2009) Reciprocal Relations Among Self-Efficacy Beliefs and Prosociality Across Time. Journal of Personality, Vol. 4, No 77, pp. 1229-1259. DOI: 10.1111/j.14676494.2009.00580.x. 
Altuna, L. (Coord.). (2008) La experiencia cooperativa de Mondragón: una síntesis general. Eskoriatza: Instituto Lanki, MU. 416 p.

Amodio, D.M. \& Keysers, C. (2018) Editorial overview: New advances in social neuroscience: from neural computations to social structures. Current opinion in psychology, No 24. DOI: 10.1016/j.copsyc.2018.10.017.

Anagün, Ş. S. (2018) Teachers' Perceptions about the Relationship between 21st Century Skills and Managing Constructivist Learning Environments. International Journal of Instruction, Vol. 4, $\mathrm{N}^{\mathrm{o}} 11$, pp. 825-840. DOI: 10.12973/iji.2018.11452a.

Anaut, L. (2004) Sobre el sistema Amara Berri. Vitoria Gasteiz: Eusko Jaurlaritzaren Argitalpen Zerbitzu Nagusia/ Servicio Central de Publicaciones del Gobierno Vasco. 308 p.

Antero, A. (2015) Konfiantzaren Pedagogia. Arrasate-Mondragón: Arizmendi Ikastola. 182 p.

Anthony, D. \& Horne, C. (2003) Gender and cooperation: explaining loan repayment in micro-credit groups. Social psychology quarterly, Vol. 3, N 66, pp. 293-302.

Aragay, X. (2017) Reimaginando la educación: 21 claves para transformar la escuela. Barcelona: Paidós. 256 p.

Armijo, M. (2018) La colaboración en educación: trayectorias de un concepto (siglo XIX-XXI). Cuadernos Chilenos de la historia de la educación, $\mathrm{N}^{\mathrm{o}} 10$, pp. 27-55. Disponible en: http://www.historiadelaeducacion.cl/index.php/CCHE/article/view/120.

Arregi, X. (2015) El modelo pedagógico de Antzuola Herri Eskola. (Tesis doctoral, Mondragon Unibertsitatea). Disponible en: $\quad$ https://katalogoa.mondragon.edu/Documentos/Tesis/HUHEZI/Tesi_Irekiak/20142015/XabierArregi_Tesia_2014-2015.pdf.

Azurmendi, J. (1984) El hombre cooperativo: pensamiento de Arizmendiarrieta. Arrasate: CLP. 862 p.

Azurmendi, J. (2016) Gizabere kooperatiboaz. Donostia-San Sebastian: Jakin. 197 p.

Blasco-Serrano, A. C., Dieste, B., y Coma, T. (2019). Actitudes en Centros Educativos respecto a la Educación para la Ciudadanía Global. REICE: Revista Iberoamericana sobre Calidad, Eficacia y Cambio en Educación, Vol. 3, № 17, pp. 79-98. DOI: 10.15366/reice2019.17.3.005.

Boletín Oficial del Estado (2015) Orden ECD/65/2015, de 21 de enero, por la que se describen las relaciones entre las competencias, los contenidos y los criterios de evaluación de la educación primaria, la educación secundaria obligatoria y el bachillerato. Disponible en: https://www.boe.es/boe/dias/2015/01/29/pdfs/BOE-A-2015-738.pdf.

Cabaleiro, M. J., Iglesias, C. y Martínez, R. (2019) Democratic firms and economic success. The co-op model. REVESCO. Revista de Estudios Cooperativos, Tercer Cuatrimestre, No 132, pp. 29-45. DOI: 10.5209/REVE.65482.

Cantero, M. P., Pérez, N. y Navarro, I. (2011) Historia y conceptos de la psicología del desarrollo. En Pérez, N.; Navarro, I. (Coord.). Psicología del desarrollo humano. Del nacimiento a la vejez. Alicante: Editorial Club Universitario, pp. 11-35.

Care, E., Griffin, P. \& Wilson, M. (Eds.). (2018) Assessment and Teaching of 21st Century Skills: Research and Applications. Heidelberg: Springer. 276 p.

Consejo de la Unión Europea. (2006) Recomendación del Parlamento Europeo y del Consejo de 18 de diciembre de 2006 sobre las competencias clave para el aprendizaje permanente. Disponible en: https://eur-lex.europa.eu/legalcontent/ES/TXT/?uri=celex\%3A32006H0962.

Daudi, P. \& Sotto, R. (1986) European cooperations in transition-the metamorphosis of homo cooperativus. Scandinavian Journal of Management Studies, Vol. 1, No 3, pp. 65-85. DOI: 10.1016/0281-7527(86)90011-3.

Dawkins, R. (1976) The selfish Gene. Fourth Edition. Oxford: Oxford University press. 496 p.

Declaration Bologna. (1999) The European Higher Education Area. Joint declaration of the European Ministers of Education Convened in Bologna on 19 June 1999. Disponible en: http://www.ehea.info/media.ehea.info/file/Ministerial_conferences/06/0/1999_Bologna_Declaration_Spanish_55306 $\underline{0 . p d f}$.

De Waal, F. B. M. (2007) El mono que llevamos dentro. Barcelona: Tusquets. 280 p.

Díaz, P. E., Díaz, R. y González, I. (2017) Validación de una escala breve de individualismo-colectivismo. Psicología Iberoamericana, Vol. 1, No 25, pp. 30-40. Recuperado de: https://www.redalyc.org/pdf/1339/133957571004.pdf.

García, L.; García, J. G. y Figueras, D. (2018) Importancia de la educación cooperativa. Una experiencia cubana. REVESCO. Revista de Estudios Cooperativos, Tercer Cuatrimestre, No 129, pp. 142-160. DOI: 10.5209/REVE.62881.

García, M., Zubizarreta, M. y Astigarraga, E. (2017) Mendeberri 2025 Marco Pedagógico. Arrasate-Mondragón: Mondragón Unibertsiatea. 82 p.

Glaser, B. G. \& Strauss, A.L. (1967) The Discovery of Grounded Theory: strategies for qualitative research. New York: Aldine.

Harari, Y. N. (2018) 21 lecciones para el siglo XXI. Barcelona: Debate. 408 p.

Inglada, E., Sastre, J. M. y LVillarroya, B. (2015) El cooperativismo en la educación. REVESCO. Revista de Estudios Cooperativos, Segundo Cuatrimestre, No 118, pp. 122-147. DOI: 10.5209/rev_REVE.2015.n118.49059.

Kasperowicz, A. (2012) Sustainable development and the Homo Sovieticus syndrome. En Visksne, I.; Vevere, V. (Eds.). Jurnal of Turiba University, Avta prosperitatis, 3. Riga: Turiba University, pp. 49-60.

Karrera, I. y Arguiñano. A. (2018) Escuelas inclusivas en el País Vasco: organización escolar y currículum emergentes y flexibles. En Arancibia, H., Castillo, P.; Saldaña, J. (Coord.). Innovación Educativa: perspectivas y desafíos. Valparaíso: Universidad de Valparaíso, pp. 139-174. 
Kliemann, D. \& Adolphs, R. (2018) The social neuroscience of mentalizing: Challenges and recommendations. Current opinion in psychology, $\mathrm{N}^{\mathrm{o}} 24$, pp. 1-6. DOI: 10.1016/j.copsyc.2018.02.015.

Kropotkin, P. (1902, 1993). Mutual Aid: a factor of evolution. London: Freedom Press.

Lacroix, J. (2001) Émile Bugnon (1880-1962), au service de la république coopérative. Revue internationale de l'économie sociale: Recma, No 279,pp. 83-88. DOI: 10.7202/1023756ar.

Lasserre, G. (1980) El hombre cooperativo. Buenos Aires: Intercoop Editora. 119 p.

Lorente, S., Martí-Vilar, M. i Puchol-Fraile, I. (2015). La competència social i la conducta prosocial en estudiants de secundària. Anuari de Psicologia de la Societat Valenciana de Psicologia, Vol. 2, No 16, pp. 175-191.

Martínez, R., Cruz, H., Blanco, I. y Salazar, Y. (2019) La innovación social, ¿prácticas para producir autonomía, empoderamiento y nueva institucionalidad?. Revista Internacional de Sociología, Vol. 22, № 77, pp. e126. DOI: 10.3989/ris.2019.77.2.17.022.

Martí Villar, M., Verdú-Ruiz, N. i Serrano-Pastor, L. (2018) Intervindre en prosocialitat a l'ambit educatiu: una revisió sistemática. Anuari de Psicologia de la Societat Valenciana de Psicologia, Vol. 1, No 19, pp. 149-171.

Martí Villar, M., Corell García, L. \& Merino Soto, C. (2019) Systematic review of prosocial behavior measures. Revista de Psicología, Vol.1, No 37, pp. 349-377. DOI: 10.18800/psico.201901.012.

Melis, A. P., Hare, B. \& Tomasello, M. (2006) Engineering cooperation in chimpanzees: tolerance constraints on cooperation. Animal Behaviour, Vol. 2, No 72, pp 275-286. DOI: 10.1016/j.anbehav.2005.09.018.

Melis, A. P. \& Tomasello, M. (2019) Chimpanzees (Pan Troglodytes) develop a successful communicative strategy to collaborate. Proceedings of the Royal Society B: Biological Sciences, $\mathrm{N}^{\circ}$ 286, pp. 1901. DOI: 10.1098/rspb.2019.0408.

Moreno, J.L. (2017) Las relaciones entre los valores y principios cooperativos y los principios de la normativa cooperativa. REVESCO. Revista de Estudios Cooperativos, Segundo Cuatrimestre, $\mathrm{N}^{\circ}$ 124, pp. 114-127. DOI: 10.5209/REVE.54923.

Musicco, G. (2018) Soft skills \& coaching: motor de la Universidad en Europa. Revista Universitaria Europea, № 29, pp. 115-132.

National Research Council. (2012) Education for Life and Work: Developing Transferable Knowledge and Skills in the 21 st Century. Washington, DC: The National Academies Press. DOI: 10.17226/13398.

Nowak, M. A. (2006) Five rules for the evolution of cooperation. Science, N ${ }^{\circ}$ 314, 1560-1563. DOI: 10.1126/science. 1133755 .

Nowak, M. A. \& Highfield, R. (2011) Supercooperators: Altruism, evolution, and why we need each other to succeed. New York: Simon and Schuster. 486 p.

Organisation for Economic Co-operation and Development. (2015) Skills for Social Progress: The Power of Social and Emotional Skills. Montreal: UIS. DOI: 10.1787/9789264226159-en.

Organización para la Cooperación y el Desarrollo Económicos. (2019) Estrategia de Competencias de la OCDE 2019: Competencias para construir un futuro mejor. Madrid: Fundación Santillana. DOI: 10.1787/e3527cfb-es.

Puentes, R. y Velasco, M. M. (2009) Importancia de las sociedades cooperativas como medio para contribuir al desarrollo económico, social y medioambiental, de forma sostenible y responsable. REVESCO. Revista de Estudios Cooperativos, Tercer Cuatrimestre, № 99, pp. 104-129.

Puig, M. y Morales, J. A. (2015) La formación de ciudadanos: conceptualización y desarrollo de la competencia social y cívica. Educación XX1, VOL. 1, № 1, pp. 259-282. DOI: 10.5944/educXX1.18.1.12332.

Raworth, K. (2018) Economía rosquilla: siete maneras de pensar como un economísta del siglo XXI. Barcelona: Paidós. 384 p.

Ruiz, J. I. (1999) Metodología de la investigación cualitativa. Bilbao: Universidad Deusto.

Saunders, B., Sim, J., Kingstone, T., Baker, S., Waterfield, J., Bartlam, B., Burroughs, H. \& Jinks, C. (2017) Saturation in qualitative research: exploring its conceptualization and operationalization. Quality \& Quantity, Vol. 4, No 52, pp. 1893-1907. DOI: 10.1007/s11135-017-0574-8.

Sennett, R. (2012) Juntos. Rituales, placeres y política de cooperación. Barcelona: Editorial Anagrama. 260 p.

Severinson, P. (2017) Approches to Assessing Impacts in the humanities and Social Sciences. Federation for the Humanities and Social Sciences. Disponible en: idees.ca/sites/default/files/sites/default/uploads/policy/2017/impact_report_en_final.pdf.

Strauss, A. L. (1987) Qualitative analysis for social scientists. Cambridge: University Press. DOI: $10.1017 / \mathrm{CBO} 9780511557842$.

Swaab, D. (2014) Somos nuestro cerebro. Cómo pensamos, sufrimos y amamos. Barcelona: Plataforma. 520 p.

Taylor, S. J. y Bogan, R. (1987) La entrevista en profundidad. En Taylor, S. J.; Bogan, R. Introducción a los métodos cualitativos de investigación. Barcelona: Paidós, pp. 100-132.

Trinidad, A., Carrero, V. y Soriano, R.M. (2006) Teoría fundamentada “Grounded Theory”: La construcción de la teoría a través del análisis interpretacional. Madrid: CIS. $175 \mathrm{p}$.

Tomasello, M. (2007) Los orígenes culturales de la cognición humana. Buenos Aires: Amorrortu. 290 p.

Tomasello, M. (2010) ¿Por qué cooperamos?. Buenos Aires: Katz Editores. 188 p.

Tomasello, M., Melis, A. P., Tennie, C., Wyman, E. \& Herrmann, E. (2012) Two key steps in the evolution of human cooperation. Current Anthropology, Vol. 6, No 53, pp. 673-692. DOI: 10.1086/668207.

Vollberg, M.C. \& Cikara, M. (2018) The neuroscience of intergroup emotion. Current opinion in psychology, $\mathrm{N}^{\mathrm{o}} 24$, pp. 48-52. DOI: 10.1016/j.copsyc.2018.05.003. 
Wagner, T. (2012) Creating innovators: The making of young people who will change de world. New York: Scribner. 304 p.

Weisz, E. \& Zaki, J. (2018) Motivated empathy: A social neuroscience perspective. Current opinion in psychology, ํㅜ 24, pp. 67-71. DOI: 10.1016/j.copsyc.2018.05.005.

Wilson, D. S. \& Wilson, E. O. (2007) Rethinking the theoretical foundation of sociobiology. The Quarterly review of biology, Vol. 4, No 82, pp. 327-348. DOI: 10.1086/522809.

Wilson, E. O. (2012). La conquista social de la tierra. Barcelona: Debate. 382 p.

World Economic Forum. (2016) New vision for education: Fostering social and emotional learning through technology. Geneva, Switzerland: http://www3.weforum.org/docs/WEF_New_Vision_for_Education.pdf.

Forum. Disponible en: 